\title{
Varieties of Second Modernity and the Cosmopolitan Vision
}

\section{Ulrich Beck}

(9SAGE

\begin{abstract}
This text was prepared for presentation in Nagoya, Japan, in 20I0. Its aim was to explore a dialogue with Asians toward a cosmopolitan sociology. Beginning from the idea of entangled modernities which threaten their own foundations, Ulrich Beck advocated a complete conceptual innovation of sociology in order to better comprehend the fundamental fragility and mutability of societal dynamics shaped by the globalization of capital and risks today. More specifically, he proposed a cosmopolitan turn of sociology: first, by criticizing methodological nationalism; second, by introducing the concept of cosmopolitization; third, by re-mapping social inequalities; fourth, by discussing risk society in the context of East Asian development; and fifth and finally, by proposing a cosmopolitan vision. Along this line, Beck attempted an overview of the researches done on second modern transformation in East Asia and suggested that an active dialogue may be possible when Asians begin to see the West from their perspectives rather than being caught in the Euro-centric and West-hegemonic presuppositions.
\end{abstract}

\section{Keywords}

cosmopolitan sociology, East Asia, methodological cosmopolitanism, methodological nationalism, risk society, second modernity

In his inspiring programmatic statement 'Meeting the Challenges of Global Sociology: From Gothenburg to Yokohama', the new President of the International Sociological Association (ISA), Michael Burawoy (2010), remains ambiguous as to whether global sociology is just an additional perspective, a supplement to the conventional nation-state centered sociology. Or is it more than that: a substitute for the mainstream, that is to say, a critical turn in sociological theory and research? The first line of argument I call 'global sociology', the second one 'cosmopolitan sociology'. The Global Dialogue (Beck, 2010) on those alternative 
visions to me seems to be most important for 'sociology on the move' in the coming years.

The collapse of a world order is the moment for reflection on the dominant social theory and research, but surprisingly this is not the case today. Mainstream social theory still floats loftily above the lowlands of epochal transformations (climate change, financial crisis, nation-states) in a condition of universalistic superiority and instinctive certainty. This universalistic social theory, whether structuralist, interactionist, Marxist, critical or systems-theory, is now both out of date and provincial. Out of date because it excludes a priori what can be observed empirically: a fundamental transformation of society and politics within modernity (from first to second modernity); provincial because it mistakenly absolutizes the trajectory, the historical experience and future expectation of Western, i.e. predominantly European or North American, modernization and thereby also fails to see its own particularity.

This is why we need not only a 'global sociology' as the coordination of national sociological organizations (as Burawoy has in mind), but a cosmopolitan turn in social and political theory and research. How can social and political theory be opened up, theoretically, empirically, as well as methodologically and normatively, to historically new, entangled modernities which threaten their own foundations (Beck, 1999, 2009)? How can it account for the fundamental fragility and mutability of societal dynamics (of unintended side-effects, domination and power), shaped, as they are, by the globalization of capital and risks at the beginning of the 21 st century? What theoretical and methodological problems arise and how can they be addressed in empirical research? Today I want to discuss these questions in five steps:

First, I will call into question one of the most powerful convictions about society and politics, one which binds both social actors and social scientists: methodological nationalism. Methodological nationalism equates modern society with society organized in territorially limited nation-states (Beck and Grande, 2010a). Second, I propose to draw an essential distinction between cosmopolitanism in a normative philosophical sense and cosmopolitization as a social scientific research programme. Third, I am going to illustrate this paradigm shift by re-mapping social inequalities; fourth, by discussing risk society and its East Asian varieties. Fifth and finally, I will pick up the question: What does a 'cosmopolitan vision' imply for the social sciences and humanities at the beginning of the 21 st century?

\section{Critique of Methodological Nationalism}

In my book Risk Society (1992) I argue that there is an epochal shift from industrial to risk societies. The former were based upon industry and social class, upon welfare states and upon the distribution of various 
goods organized and distributed through the state, especially of good health, extensive education, and equitable forms of social welfare. There were state-organized societies, there was a national community of fate, and there were large-scale political movements, especially based upon industrial class divisions that fought over the distribution of their various 'goods'. In the post-war period in Western Europe there was a welfare state settlement in such industrial societies based upon achieving a fairer distribution of such goods.

By contrast the concept of risk society is based on the importance of bads. Risk societies involve the distribution of bads that flow within and across various territories and are not confined within the borders of a single society. Nuclear radiation is a key example of this, but also financial risks, global warming, SARS, etc. These risks cannot be confined into any scientific space or into any current sector of time. Such risks thus cannot be insured against. They are uncontrolled and the consequences incalculable. This argument about the 'borderlessness' of the risk society has, together with the writings of many others, developed the analysis of 'globalization' implications for sociology. I have especially shown the nature and limitation of methodological nationalism. What does this mean and what is wrong with it?

In brief: methodological nationalism assumes that the nation, state and society are the 'natural' social and political forms of the modern world. Where social actors subscribe to this belief I talk of a "national outlook'; where it determines the perspective of the social scientific observer, I talk of 'methodological nationalism'. The distinction between the perspective of the social actor and that of the social scientist is crucial, because there is only a historical connection between the two, not a logical one. This historical connection - between social actors and social scientists - alone gives rise to the axiomatics of methodological nationalism. Methodological nationalism is neither a superficial problem nor a minor error (Beck and Grande, 2010a). It involves both the routines of data collection and production as well as the basic concepts of modern sociology and political science, concepts such as society, social class, state, family, democracy, international relations, etc.

Moreover, sociologists tended to generalize from 'their' particular society to a claim about how 'society' in general is organized (this holds also for my book Risk Society [1992]). American sociology, in particular, developed in this way, presuming that all societies were more or less like that of the USA, just poorer! It was perfectly possible to study that particular society and then to generalize as though all, or at least most, other societies (at least those that mattered!) were much the same. This led to debates about the general nature of order or of conflict within 'society' based upon the distinct US pattern. Order and conflict theories were to be 'tested' within the USA and it was presumed that these conclusions could then be generalized to all societies, or at least to 
all rich industrial societies. For decades it was simply how sociology worked; it was a taken-for-granted way of doing sociology - then 'global studies' marched in.

\section{How to Research the Global: We Do not Live in an Age of Cosmopolitanism but in an Age of Cosmopolitization}

We can distinguish three phases in the way the word 'globalization' has been used in the social sciences: first, denial; second, conceptual refinement and empirical research; third, 'cosmopolitization'. The initial denial is over because the theoretical and empirical refinement revealed a new social landscape in the making (see Held and McGrew, The Global Transformations Reader, 2003). Its dominant features include interconnectedness, which means dependency and interdependency of people across the globe. Virtually the entire span of human experiences and practices is in one way or another influenced by the overwhelming interconnectivity of the world. (This should not be confused with world system and dependency theories.)

The third phase uncovers the core unseen, unwanted consequence of this global interconnectivity: really existing cosmopolitization - the end of the 'global other'. The global other is here in our midst. This is precisely the point: to clearly distinguish between philosophical cosmopolitanism and social scientific cosmopolitization.

Cosmopolitanism in Immanuel Kant's philosophical sense means something active, a task, a conscious and voluntary choice, clearly the affair of an elite, a top-down issue. But today in reality a 'banal', 'coercive' and 'impure' cosmopolitization unfolds unwanted, unseen - powerful and confrontational beneath the surface or behind the façade of persisting national spaces, jurisdictions and labels. It extends from the top of the society down to everyday life in families, work situations and individual biographies - even as national flags continue to be raised and even if national attitudes, identities and consciousness are strongly being reaffirmed. Banal cosmopolitization is, for example, seen in the huge array of foodstuffs and cuisines routinely available in most towns and cities across the world. It is possible with enough money to 'eat the world'. What others have viewed as a 'postmodern eclecticism' I see not against the modern but as rather a new reflexivity about what modernity is. Thus, cuisines, global risk, art and global cultural conflicts (for example, about the Danish Mohammed cartoons) are assembled, compared, juxtaposed, and reassembled out of diverse components from multiple countries around the world. So the new volcanic landscapes of 'societies' and their radicalized social inequalities have to be re-mapped on the macro level as well as on the micro level, and projected horizontally through communication, interaction, work, economy and, indeed, all such social and political practices. 
Like climate change, most of the main impetuses for social and economic transformations in the new century, as Chang Kyung-Sup (2010) argues, do not differentially or exclusively apply to certain limited groups of nations. Consider the following: global free trade and financialization, corporate deterritorialization and transnationalized production, globalized labor use, competition and class conflicts, globalized policy consulting and formulation (coerced by the IMF, etc.), internet communication and cyberspace, globally orchestrated bioscientific manipulation of life forms (gradually including human bodies), global risks of all kinds (financial crisis, terrorism, AIDS, swine flu, SARS), transnational demographic realignments (migration of labor, spouses, children), cosmopolitanized arts and entertainments and, last but not least, globally financed and managed regional wars. There are no permanent systematic hierarchies, sequences or selectivities by which different groups of nations whether at different levels of development, in different regions or of different ethnicities and religions - are exposed to these new civilizational forces in mutually exclusive ways. Wanted or not, they are every nation's and every person's concern because they are structurally enmeshed with the new civilization process which I call '(reflexive) cosmopolitization'; and the civilizational condition thereby shared across the globe is '(reflexive or) second modernity' (Chang, 2010: 444-5).

The recent world history seems to dictate that surviving, let alone benefiting from, these new civilizational forces requires every nation to actively internalize them and one another. The sociological implication is: the other is in our midst! Isolationist efforts - whether spoken of in terms of trade protectionism, religious fundamentalism, national fundamentalism, media and internet control or whatever else - are readily subjected to international moral condemnations (and are, to some extent, ineffective). In fact, accepting or refusing these forces remains beyond willful political or social choices because they are globally reflexive that is, compulsively occurring through the 'cosmopolitan imperative: cooperate or fail!'

It has become a commonplace that national institutions alone are unable to cope with the challenges of regulating global capitalism and responding to new global risks (Beck, 1999, 2009). It is no less obvious that there is no global state or international organization capable of regulating global capital and risk in a way comparable to the role played by the European welfare national state in first modernity. Instead, we can observe a complex reconstitution of political authority, with which to organize the mechanisms of global economic regulation, risk management and control in ways characterized by new forms of political interdependence (Grande and Pauly, 2005). At present, the politics of the 'world risk society' is an extraordinarily intricate terrain, composed, among other things, of co-ordinated national mechanisms, bilateral and multilateral agreements, inter-, trans- and supranational 
institutions, transnational corporations, private charity foundations, and civil society groups.

Despite this rapidly growing number of global organizations and transnational institutions, there is an increasing unease, nourished not least by the hesitant responses to the global financial crisis, the European currency crisis, and the poor results of the last global climate conference at Copenhagen, that these institutions are proving unable to address the challenges they were created to meet. Similar developments can be observed at the national level regarding, for example, democratic institutions, welfare systems, families, etc. Can the World Bank solve the global problem of poverty? Can the Food and Agriculture Organization of the United Nations (FAO) solve a global food crisis? Can the World Trade Organization effectively regulate global trade? It seems as if these institutions do not constitute a sufficient basis for managing or controlling the global risks and crises created by the global victory of industrial capitalism.

This is exactly what the transformative dynamics of the second, cosmopolitan modernity is about! Isn't there a gulf of centuries between the threats, opportunities and conflict dynamics of border-transcending, radicalized modernization in the 21 st century and the ideas, institutions and structures of industrial capitalism and national state authority rooted in the 19th century (Held and McGrew, 2003)?

\section{Re-mapping Social Inequality beyond Methodological Nationalism}

Although we still study social inequality - and indeed, across the globe, inequalities seem to have increased - it is less clear that social class is the principal unit of analysis and investigation. I rather provocatively developed the argument that individualization is the social structure of the second modernity, and this produces non-linear, open-ended, and ambivalent consequences. This is again a very different vision from most sociology focused around the 'zombie concepts' of the first modernity, especially the idea that social class based on occupational division is the key element within social structures and that the object of class struggle is to transform the state.

I have developed four points here: First, poverty is no longer a characteristic of those within the working class. It is something that many people will now experience, especially including young middle-class people undergoing higher education. Second, the world of a second modernity is a world of unbelievable contradictions and contrasts where super-modern castles or citadels are constructed next to scenes of Apocalypse Now (as with the now destroyed World Trade Center in New York, with thousands of beggars living in the subway below). Class hardly captures such shimmering inequality. Third, the major 
movements of change have little to do with class, even that responsible for the most stunning transformation of the past three decades, such as the financial crisis of 2008, '9/11' and the dramatic and unpredicted bringing down of the Soviet empire by various rights-based social networks. Fourth, the national outlook on social inequality is inward orientated. It stops at the borders of the nation-state. Social inequalities may blossom and flourish on the other side of the national garden fence - that is, at best, cause for moral outrage, but politically irrelevant.

A clear distinction must be made, therefore, between the reality of social inequality and the political problem of social inequality. National boundaries draw a sharp distinction between politically relevant and irrelevant inequality. Inequalities within national societies are enormously magnified in perception; at the same time inequalities between national societies are faded out. The 'legitimation' of global inequalities is based on an institutionalized 'looking the other way'. The national gaze is 'freed' from looking at the misery of the world. It operates by way of a double exclusion: It excludes the excluded. And the social science of inequality, which equates inequality with nation-state inequality, is unreflectively party to that. It is indeed astonishing how firmly global inequalities are 'legitimated' on the basis of tacit agreement between nation-state government and nation-state sociology - a sociology programmed to work on a nation-state basis and claiming to be value-free!

My point is: The performance principle legitimates national inequality, the nation-state principle legitimates global inequality (in another form). How? The inequalities between countries, regions and states are accounted politically incomparable. In a perspective bounded by nation-state, politically relevant comparisons can only be played out within the nation-state, never between states. Such comparisons, which make inequality politically explosive, assume national norms of equality. That is why even massive differences in income between persons with the same qualifications but different nationality only then have a political force if they can be related to a horizon of perception of common equality. Such a common frame only emerges when the persons belong to the same nation or the European union of states or are employed in the same company, even if in different national subsidiaries.

Yet that is precisely what the national gaze fades out: The more norms of equality spread worldwide, the more global inequality is stripped of the legitimation basis of institutionalized looking away (Beck, 2009). The wealthy democracies carry the banner of human rights to the furthest corners of the earth, without noticing that the national border defences, with which they want to repel the streams of migrants, thereby lose their legitimation. Many migrants take seriously the proclaimed human right of equality of mobility and encounter countries and states which - not least under the impact of increasing internal inequalities - want the norm of equality to stop short at their fortified borders. Put in other words that 
means: The conception of social inequality, based on principles of nationality and statehood, misleads analysis. Most theorists of class, including Bourdieu, who thought so extensively about globalization in his final years, identify class society with the nation-state. The same is true of Wallerstein, Goldthorpe, in fact also of almost all non-class theory sociologists of inequality (and incidentally also of my individualization thesis).

\section{Risk Society and its East Asian Varieties}

Why is the concept of '(world) risk society' so important in order to understand the social and political dynamics and transformations at the beginning of the 21st century? It is the accumulation of risks - ecological, financial, military, terrorist, biochemical and informational - that has an overwhelming presence in our world today (Beck, 1999; Beck and Grande, 2010b). To the extent that risk is experienced as omnipresent, there are only three possible reactions: denial, apathy and transformation. The first is largely inscribed in modern culture but ignores the political risk of denial; the second gives way to a nihilistic strain in postmodernism; the third marks the issue the theory on global risk society raises: How does the anticipation of a multiplicity of man-made futures and its risky consequences affect and transform the perceptions, living conditions and institutions of modern societies?

In order to answer this question we first have to distinguish between risk and catastrophe. Risk does not mean catastrophe. Risk means the anticipation of catastrophe. Risks are about staging the future in the present, whereas the future of future catastrophes is in principle unknown. Without techniques of visualization, without symbolic forms, without mass media, without art, risks are nothing at all. The sociological point is: If destruction and disaster are anticipated this might produce a compulsion to act. The social construction of a 'real' anticipation of future catastrophes in the present (like climate change, or financial crisis) can become a political force, which transforms the world (for the better or the worse).

In a second step we then have to distinguish between three types of future uncertainties: threats, risks and manufactured uncertainties. The risk society thesis always encounters the objection: Have not endangerment and insecurity belonged to human existence from its beginnings, in earlier ages seemingly more so then today (sickness, short life expectancies, wars, and epidemics)? This is true, but according to a conventionally agreed distinction, this is not 'risk' but a 'threat'. Again we have to make the following distinction: 'risk' is a modern concept, risk presupposes human decisions, humanly made futures (probability, technology, modernization). This first modern concept of risk has to be distinguished from 'manufactured uncertainties' (second modernity). 
Typically today, communication and conflict flare up around this particular type of new manufactured risk (Beck, 2009). Neither natural disasters - threats - coming from the outside and thus attributable to God or nature, such as prevailed in the pre-modern period, have this effect any longer (they do in religious cultures). Nor do the specific calculable uncertainties - risks that are determinable with actuarial precision in terms of a probability calculus backed up by insurance and monetary compensation, such as were typical of first modern industrial society, fall in this category. At the centre of risk societies are 'manufactured uncertainties'. They are distinguished by the fact that they are dependent on human decisions, created by society itself, immanent to society and thus not externalizable, collectively imposed and thus individually unavoidable; their perceptions break with the past, break with experienced risks and institutionalized routines.

Threat, risk and manufactured uncertainty can be differentiated in ideal-typical terms as outlined here, but in reality they intersect and commingle. In fact, the problems of drawing hard and fast distinctions between these politically very differently valued aspects of future uncertainty comprise a decisive focus and motor of risk conflicts.

These are some elements of the European model of world risk society. How has this model to be modified examining various types of risks associated with East Asian 'compressed modernity'? The Korean sociologists Sang-Jin Han and Young-Hee Shim (2010) even conclude that 'the concept of risk society is more relevant to East Asia than to Western societies' - but it has to be redefined. They distinguish two modes of risk production in contemporary societies. On the one hand, 'new global risks' produced by a radicalization of the first, industrial modernity, have been emerging. These so-called 'manufactured uncertainties' are the dominant type of risk in Western, in particular West European, societies. Examples are climate change, transnational terrorism and systemic economic risks. However, Han and Shim argue that 'it is wrong to conceptualize all risks along this way. On the other hand, certain types of risk are produced as consequences of the deficiencies built into the rushto strategy of development in East Asia' (Han and Shim, 2010: 471). Examples of these 'deficiency risks' are large-scale accidents of various kinds, violence, contamination of foods and tap water, fraudulent construction projects, earth breaks which destroy cities, dislocation of the family and so on.

Han and Shim also distinguish two different modes of risk dispersion: transnational and regional: "Risks may be called "transnational" if they can, in principle, happen everywhere in the world. In contrast, risks may be "regional" if they tend to occur not everywhere but in those specific countries that merge into a particular pathway to modernity' (Han and Shim, 2010: 471).

The 'deficiency risks' produced by the rush-to strategy of modernization in East Asia are mostly regional in scope. They affect East Asian 
countries in a specific way, although they materialize in a global context. As a result, risk society in East Asian countries takes a completely different shape than in Western Europe. It is constituted by different risks, different risk cultures and different risk conflicts. Han and Shim conclude that by examining 'world risk society', we need to focus also on the concrete reality of East Asia. This is not because the Western view of global risks lacks validity, but because other types of risks, which originate from deficiencies of rush-to modernization, call for attention that is no less urgent in East Asia (Han and Shim, 2010).

I want to pick up this line of argument very shortly, illustrating how in second modernity and its process of individualization the decision to marry and have children in order to experience family life as a 'haven in the heartless, capitalistic world' turns into an incalculable risk. How does individualization crystallize in East Asia, especially in Japan? Which indicators do speak for individualization, which against it? (What I have to say is only a product of 'second hand sociology' which urgently needs to be corrected by those who are experts on the subject.) From the late 1990s Japanese women have utilized their increase in personal freedom in seemingly undermining social reproduction, a domain which has been conceived and deployed almost exclusively as a private concern by the state as well as its citizens. Since social reproduction has remained in the private realm without significant public support or intervention, women's personal decisions did have a quiet but critical impact. This is a crucial indicator for individualization: the significant decrease in population (and, as you know, South Korea and Japan are close to world championship in this domain).

There are additional connected indicators of individualization: By deferring, forgoing or ending marriage, refusing to produce more than one or two offspring (or to procreate at all) or by courageously rejecting family ties beyond the nuclear unit, Japanese women have taken their society by surprise. All of a sudden, these tacit yet highly effective trends have begun to be widely recognized by policy officials and academics alike as a demographic risk to the social sustainability of the national economy, and that of the nation itself.

There is an important distinction to be made between 'individualization' as a structural process and 'individualism' as a normative ideology or philosophy. Is there a phenomenon which could be called 'individualization without individualism', as Chang and Song (2010) argue? Or to say it differently: an 'individualization with familialism' (Shim and Han, 2010)? With this I mean that the facts of individualization are combined with the rhetoric of family values.

In first modernity the nuclear family was - as Talcott Parsons argues in his functionalistic model of the modern national society - a key unit of the social reproduction of the nation-state. What are the functions of family life in second modernity in Japan (and other East Asian countries 
or Europe)? My suggestion is that families are not confronted with fewer functions and burdens but that they have become functionally overloaded and socially risk-ridden (see Chang and Song, 2010). Especially the function of social security has been 'externalized' from Japanese corporations to Japanese families. But to interpret this as a 'turn back to family' would be mistaken, since the structural process of individualization has not been disrupted. The more women succeed in (higher) education and in taking over positions in the labour market, the more patriarchal hierarchy in family and society is becoming dysfunctional and being questioned. Actually, from a sociological point of view, there is a paradox of $r e$-familialization and $d e$-familialization (reducing the effective scope of family life and relations) at the same time. One of the implications of this contradictory trend is (as I said before) that the decision to marry and have children becomes an incalculable risk!

\section{A 'Cosmopolitan Vision' for the Social Sciences}

What are the more general theoretical implications of such exemplary deconstruction and re-construction? The first insight is that the progression from pre-modernity to the first modernity and second modernity is not universal and cannot be generalized. On the contrary, this progression is a central feature of the particular European path to modernity. The false universalism implicit in sociological theories cannot be uncovered by looking at Europe from a European standpoint. It can only be 'seen' by looking at Europe from a non-European perspective, that is with 'Asian eyes' - in other words, by practising methodological cosmopolitanism! Methodological cosmopolitanism not only includes the other's experiences of and perspectives on modernization but corrects and redefines the self-understanding of European modernity.

It is a paradox that the very lively debates on cosmopolitanism and cosmopolitization are - as Craig Calhoun argues:

overwhelmingly Euro-American. They are about globalization, and about risks, rights, and responsibilities in an interconnected world, but they reflect disproportionately views from the old 'core' of the modern world system (and Western-educated elites from formerly colonial outposts). This is the source of at least four biases.

First, though an effort is made to include consideration of poor, developing, or emerging economies, cosmopolitan theories reflect the perspective of the rich. Second, though an effort is made to be multicultural, cosmopolitan theories are rooted in the West. Third, the way in which most cosmopolitan theories try to escape cultural bias is by imaging an escape from culture into a realm of the universal (as though those who travel aren't still shaped by their 
previous cultural contexts and as though there the global circuits themselves don't provide new cultural contexts). Fourth, despite attention to social problems, because cosmopolitan theories are rooted in the (declining) core of the modern world system, they tend to imagine the world as more systematically and uniformly interconnected than it is. (Calhoun, 2010: 597-8)

Those biases are exactly what cosmopolitan sociology has to overcome. Let me end by summarizing in seven theses that the cosmopolitan turn entails:

1. An earlier phase of modernity was organized primarily in terms of nationstates, which sought to manage many of the risks people faced, although markets and other phenomena did cross state boundaries.

2. Modern social and political theory grew with the dominance of nation-states and internalized the nation-state as the tacit model for the ideal-as-society influenced by the actual power of nation-states but also by the widespread aspiration to organize the world on the basis of nation-states.

3. An earlier philosophical cosmopolitanism developed in this context, calling on people ethically to transcend narrow nationalist views, as though the sociological conditions of their lives did not really matter.

4. Consider global free trade and financialization, corporate deterritorialization and transnationalized production, globalized labour use, internet communication, globally orchestrated bioscientific manipulation of life forms and, last but not least, globally financed and managed regional wars. Recent world history seems to dictate that surviving, let alone benefiting from, these new civilizational forces requires every nation to actively internalize them and one another. This is what I call '(reflexive) cosmopolitization', and the civilizational condition shared across the globe is called 'reflexive' or 'second' modernity.

5. I do not see the nation-state as disappearing. I see it as only one of many actors in a global power game. The focus needs to be on that global power game and not on the nation-state.

6. Such a shift in focus requires the restructuring of the social sciences not only conceptually, theoretically, and methodologically but also in the very organization of research. All their fundamental concepts - especially the nation-state - need to be re-examined. Many are 'zombie concepts' that continue to live on even though the world that they related to at one time no longer exists.

7. Cosmopolitan sociology not only involves a fundamental reorganization of the social sciences, and a dramatic shift in focus - from methodological nationalism to methodological cosmopolitanism - but it must also be critical in its orientation. One critical focus must be on the increasing inequality in the world. The focus on the nation-state has led to a shameful subordination of 'objective' and 'value-free' sociology to the imperatives of the nation-state 
which blinds even empirical sociology to the fundamental transnational transformations of domination and inequality.

There are risks as well as opportunities in the cosmopolitan turn, but for now let us kiss the frog and then find out if the frog turns into a prince one that begins to re-map the landscapes, flows, new lines of conflict, actors and institutions of the cosmopolitan age. After all, kissing doesn't hurt anybody, does it? ${ }^{1}$

\section{Notes}

This text is from Ulrich Beck's public lecture during the Annual Meeting of the Japanese Sociological Society at Nagoya University, Japan, on 6 November 2010. This publication of the English translation of that lecture is by kind permission of Elisabeth Beck-Gernsheim.

1. For this debate on cosmopolitan sociology and for all quotations see Beck and Grande (2010a, 2010b).

\section{References}

Beck U (1992) Risk Society. London: Sage.

Beck U (1999) World Risk Society. Malden: Polity Press.

Beck U (2009) World at Risk. Cambridge: Polity Press.

Beck U (2010) Kiss the frog: The cosmopolitan turn in sociology. Global Dialogue 1(2). Available at: http://isa-global-dialogue.net/kiss-the-frog-a-cos mopolitan-turn-in-sociology/ (accessed July 2015).

Beck U and Grande E (2010a) Jenseits des methodologischen Nationalismus. Soziale Welt 61(3/4): 187-216.

Beck U and Grande E (eds) (2010b) Varieties of second modernity: ExtraEuropean and European experiences and perspectives. British Journal of Sociology 61(3): 409-443.

Burawoy M (2010) Meeting the challenge of global sociology - from Gothenburg to Yokohama. Global Dialogue 1(1). Available at: http://isaglobal-dialogue.net/meeting-the-challenge-of-global-sociology-from-gothen burg-to-yokohama/ (accessed July 2015).

Calhoun C (2010) Beck, Asia and second modernity. British Journal of Sociology 61(3): 597-619.

Chang K (2010) The second modern condition? Compressed modernity as internalized reflexive cosmopolitization. British Journal of Sociology 61(3): 444-464.

Chang K and Song M (2010) The stranded individualizer under compressed modernity: South Korean women in individualization without individualism. British Journal of Sociology 61(3): 539-564.

Grande E and Pauly LW (eds) (2005) Complex Sovereignty: Reconstituting Political Authority in the Twenty-First Century. Toronto: University of Toronto Press.

Han S and Shim Y (2010) Redefining second modernity for East Asia: A critical assessment. British Journal of Sociology 61(3): 465-489. 
Held D and McGrew A (eds) (2003) The Global Transformations Reader: An Introduction to the Globalization Debate. Cambridge: Polity Press.

Shim Y and Han S (2010) Family-oriented individualization and second modernity: An analysis of transnational marriages in Korea. Soziale Welt 61(S): 235-253.

Ulrich Beck was a Professor of Sociology at the Ludwig Maximilian University of Munich and, from 2013, the Principal Investigator of the European Research Council (ERC) project 'Methodological Cosmopolitanism - In the Laboratory of Climate Change'. From 1997 he had been the British Journal of Sociology Visiting Centennial Professor at the London School of Economics and, from 2011, a Professor at the Fondation Maison des Sciences de l'Homme, Paris. He had a special interest in East Asia: he co-organized the Seoul Conference on Climate Change in July 2014 and attended the World Congress of Sociology at Yokohama. He was the author or editor of more than 45 books, which have been translated into more than 35 languages.

This article is part of the Theory, Culture \& Society special section, 'Ulrich Beck in Asia: In Commemoration', edited by Sang-Jin Han. 